\title{
Influence of powder/liquid ratio on the radiodensity and diametral tensile strength of glass ionomer cements
}

\author{
Rodrigo Borges FONSECA ${ }^{1}$, Carolina Assaf BRANCO², Paulo Sérgio QUAGLIATTO4 ${ }^{4}$, Luciano de Souza GONÇALVES ${ }^{3}$, \\ Carlos José SOARES ${ }^{4}$, Hugo Lemes CARLO ${ }^{5}$, Lourenço CORRER-SOBRINHO ${ }^{6}$
}

\author{
1- DDS, MS, PhD, Professor at Federal University of Goiás, Dental School, Restorative Dentistry Area, Goiânia, GO, Brazil. \\ 2- DDS, MS, PhD student, Ribeirão Preto Dental School, São Paulo University, Ribeirão Preto, SP, Brazil. \\ 3- DDS, MS, PhD student, Department of Dental Materials, Piracicaba Dental School, State University of Campinas, Piracicaba, SP, Brazil. \\ 4- DDS, MS, PhD, Professor, Department of Operative Dentistry and Dental Materials, Dental School, Federal University of Uberlândia, Uberlândia, MG, Brazil. \\ 5- DDS, MS, PhD, Professor, Department of Restorative Dentistry, Dental School, Federal University of Pernambuco, Recife, PE, Brazil. \\ 6- DDS, MS, PhD, Professor, Department of Dental Materials, Piracicaba Dental School, State University of Campinas, Piracicaba, SP, Brazil.
}

Corresponding address: Rodrigo B. Fonseca - Faculdade de Odontologia - Universidade Federal de Goiás - Praça Universitária esquina com $1^{\text {a }}$. Avenida, s/n, Setor Universitário - Goiânia - GO - Brasil - 74605-220 - e-mail: rbfonseca.ufg@gmail.com - Phone: +55-62-32096325 - Fax: +55-62-32096054

Received: February 18, 2009 - Modification: September 6, 2009 - Accepted: October 9, 2009

\section{ABSTRACT}

\begin{abstract}
Cinicians tend to make reductions in glass ionomer power/liquid $(\mathrm{P} / \mathrm{L})$ ratios since some materials are difficult to mix and flow into small cavities, grooves or pits. In general, changing the $\mathrm{P} / \mathrm{L}$ ratio decreases the physical and mechanical properties of conventional glass ionomer cements (GICs) and resin modified glass ionomer cements (RMGICs), but alterations seem to depend on their composition. Objective: To determine the influence of $P / L$ ratio on the radiodensity and diametral tensile strength (DTS) of glass ionomer cements. Material and Methods: There were 2 factors under study: P/L ratio (manufacturer's recommended $\mathrm{P} / \mathrm{L}$ ratio and a $50 \%$ reduced $\mathrm{P} / \mathrm{L}$ ratio), and materials (Vitro Molar, Vitro Fil, Vitro Cem conventional GICs and Vitro Fil LC, Ortho Glass LC RMGICs. Five 1-mm-thick samples of each material-P/L ratio were produced for radiodensity evaluation. Samples were $x$-ray exposed onto Digora phosphor plate and radiodensity was obtained using the software Digora for Windows $2.5 \mathrm{Rev}$ 0. For DTS, five $(4.0 \times 8.0 \mathrm{~mm})$ cylinder samples of each material were tested $(0.5 \mathrm{~mm} / \mathrm{min})$. Data were subjected to one- and two-way ANOVA ( $5 \times 2)$ followed by Tukey's HSD test, or Kruskal-Wallis and Dunn's method. For paired comparisons, t-test or Mann-Whitney test were used $(\alpha=0.05)$. Results: There was a significant interaction $(\mathrm{P}=0.001)$ for the studied factors (materials $\mathrm{Vs} . \mathrm{P} / \mathrm{L}$ ratio). Reduced $\mathrm{P} / \mathrm{L}$ ratio resulted in significantly lower DTS for the RMGICs, but radiodensity was affected for all materials $(P<0.05)$. Conclusions: Reduced $P / L$ ratio affected properties of the tested glass ionomer cements. RMGICs were more susceptible to lower values of DTS, but radiodensity decreased for all materials following $\mathrm{P} / \mathrm{L}$ ratio reduction.
\end{abstract}

Key words: Tensile strength. Glass ionomer cements. Radiography. Microscopy, electron, scanning.

\section{INTRODUCTION}

Glass ionomer cements have wide spread clinical indications, being used as bases, liners, luting agents, and temporary and restorative dental materials ${ }^{17}$. The reasons for such a useful clinical versatility are related to the constant fluoride release $^{6}$, adhesion to dental tissues and base metals ${ }^{11,12,25}$, biocompatibility and low coefficient of thermal expansion ${ }^{15,23,25}$. Resin-modified glass ionomer cements (RMGICs) extended these clinical applications since they present better mechanical properties due to the polymeric nature ${ }^{24}$, overcoming some shortcomings of conventional GICs, such as surface crazing during dehydration, brittleness and low fracture strength ${ }^{22}$.

The setting reaction of glass ionomers depends on composition. Conventional GICs set by mans of an acid-base reaction in which a polyacid attacks powder particles, forming a mass with 
some interstitial spaces. According to Nicholson ${ }^{16}$ (1998), GICs consist of interpenetrating networks of inorganic and organic components forming a matrix in which particles of unreacted glass are embedded. In addition to this ionic cure, RMGICs have also a resinous polymer-based reaction due to the presence of visible light-polymerizable components ${ }^{14}$. Both reactions are processed at the same time; however, light polymerization results in a rapid initial set while the acid-base reaction, which proceeds normally from the point of mixing, slows down or becomes virtually inhibited by network formation after irradiation ${ }^{26}$.

Several aspects have been studied in order to improve the mechanical and physical properties of GICs, such as composition ${ }^{25}$, viscoelastic properties ${ }^{24}$, fracture toughness ${ }^{15,24}$, powder particle size reduction ${ }^{15}$ radiodensity ${ }^{9,10,20}$, strength ${ }^{6,11}$ and powder/liquid $(\mathrm{P} / \mathrm{L})$ ratio $^{9}$. Composition seems to be the most important factor which affects the radiopacity of dental materials ${ }^{9,10}$. In addition, the material thickness ${ }^{9,10}, \mathrm{x}$-ray beam angulation, methodology ${ }^{21}$, type of $x$-ray film, age of developing and fixing solutions ${ }^{4}$, and alteration in $\mathrm{P} / \mathrm{L} \mathrm{ratio}^{9}$ can also have an influence. The first radiopaque GICs were cermet-containing or metal reinforced cements, in which metals were responsible by high radiodensity levels ${ }^{16}$. After that, the addition of radiopaque fillers resulted on sufficiently radiopaque $\mathrm{GICs}^{5}$, which could be detected against a background of enamel and dentin, facilitating the evaluation of many clinical situations.

The diametral tensile strength (DTS) is one of the most common and useful mechanical properties of GICs, being extensively found in many studies ${ }^{18,23-25}$.
Depending on the clinical application, GICs should be strong enough to resist stresses generated within it when loaded with occlusal forces, as it is truth for luting materials ${ }^{11}$. The type of material, filler size and proportion, addition of metals, composition and $\mathrm{P} / \mathrm{L}$ ratio are factors which affect strength of $\mathrm{GICs}^{7,11,15,23-25}$. Increased $\mathrm{P} / \mathrm{L}$ ratios tend to increase DTS of GICs ${ }^{11}$. Mechanically, RMGICs generally exhibit substantial plastic deformation in compression and conventional GICs display brittle fracture ${ }^{24}$. Clinicians tend to make reductions in glass ionomer $\mathrm{P} / \mathrm{L}$ ratios since some materials are difficult to $\mathrm{mix}^{13}$ and flow into small cavities, grooves or pits $^{2}$. In general, changing the $\mathrm{P} / \mathrm{L}$ ratio decreases the physical and mechanical properties of conventional GICs and RMGICs depending on the reduction of powder per volume ${ }^{15}$.

There is the chance of altering the DTS and radiodensity of GICs due to reduced $\mathrm{P} / \mathrm{L}$ ratios, which could virtually lessen the longevity of clinical procedures. Then, the aim of this study was to determine the influence of a $50 \%$ reduction in $\mathrm{P} / \mathrm{L}$ ratio on the DTS and radiodensity of different conventional GICs and RMGICs.

\section{MATERIAL AND METHODS}

Five GICs (DFL, Rio de Janeiro, Brazil) with different clinical indications were employed in this study. Material applications, commercial names, batch numbers and composition are listed in Figure 1. Two tests were performed in order to analyze the effect of reducing the $P / L$ ratio of different GICs: Radiodensity and DTS. Groups were formed according to 2 experimental factors under study:

\begin{tabular}{|l|l|l|l|}
\hline $\begin{array}{c}\text { Commercial } \\
\text { Name/ }\end{array}$ & $\begin{array}{c}\text { Batch } \\
\text { number }\end{array}$ & \multicolumn{1}{|c|}{ Application } & \multicolumn{1}{|c|}{ Composition } \\
\hline Vitro Molar & 6050868 & $\begin{array}{l}\text { ART technique. Cervical restorations } \\
\text { in posterior teeth. Core build-up. } \\
\text { Temporary restorations. }\end{array}$ & $\begin{array}{l}\text { Powder: Barium and aluminum silicate, FeO, } \\
\text { dehydrated polyacrylic acid. Liquid: polyacrylic acid, } \\
\text { tartaric acid, distilled water }\end{array}$ \\
\hline Vitro Cem & 6060935 & Luting. Lining. & $\begin{array}{l}\text { Powder: Strontium and aluminum silicate, FeO, } \\
\text { dehydrated polyacrylic acid. Liquid: polyacrylic acid, } \\
\text { tartaric acid, distilled water }\end{array}$ \\
\hline Vitro Fil & 6060987 & $\begin{array}{l}\text { Temporary restorations. Fissure } \\
\text { sealing. Core build-up. Lining. }\end{array}$ & $\begin{array}{l}\text { Powder: Strontium and aluminum silicate, FeO, } \\
\text { dehydrated polyacrylic acid. Liquid: polyacrylic acid, } \\
\text { tartaric acid, distilled water }\end{array}$ \\
\hline Vitro Fil LC & 6060941 & $\begin{array}{l}\text { Restorations of anterior permanent } \\
\text { and deciduous teeth, and posterior } \\
\text { deciduous teeth. Core build-up. } \\
\text { Cavity liner. }\end{array}$ & $\begin{array}{l}\text { Powder: Strontium and aluminum silicate, excipients, } \\
\text { activators, FeO. Liquid: Hema, polyacrylic and tartaric } \\
\text { acid, benzoyl peroxide, camphorquinone. }\end{array}$ \\
\hline Ortho Glass LC & 6061021 & $\begin{array}{l}\text { Bonding of orthodontic brackets and } \\
\text { bands. }\end{array}$ & $\begin{array}{l}\text { Powder: Strontium and aluminum silicate, fumed } \\
\text { silica, activators, FeO. Liquid: HEMA, polyacrylic } \\
\text { acid, activators, co-activators and camphorquinone. }\end{array}$ \\
\hline
\end{tabular}

* HEMA, 2-hydroxyethylmethacrylate

Figure 1- Restorative materials used in the study 
materials, with 5 levels (Figure 1 ) and P/L ratio, with 2 levels, the manufacturer's recommended $\mathrm{P} / \mathrm{L}$ ratio and a $50 \%$ reduced $\mathrm{P} / \mathrm{L}$ ratio. Samples were fabricated at room temperature according to each experimental method, as described below. Chemical cured materials were allowed to set during the period recommended by each manufacturer. Light-cured materials were photoactivated for $40 \mathrm{~s}$ with a halogen curing unit (XL3000; 3M ESPE, St. Paul, MN, USA) at $850 \mathrm{~mW} / \mathrm{cm}^{2}$.

\section{Radiodensity Test}

Five 1-mm-thick ring-shaped standard samples were fabricated for each experimental group by mixing the materials according to the manufacturers' instructions and inserting them in a 1-mm-thick stainless steel mold with diameter of $4.0 \mathrm{~mm}$. After removal of the samples from the mold, the thickness was checked with a digital caliper in order to fit 1.0 $\mathrm{mm}( \pm 0.1 \mathrm{~mm})$. An aluminum stepwedge, ranging from $1.0 \mathrm{~mm}$ to $9.0 \mathrm{~mm}$ in thickness, served as a control.

The samples were positioned onto a phosphor plate and radiographic exposure was performed for $0.2 \mathrm{~s}$ at $70 \mathrm{kV}$ and $10 \mathrm{~mA}$, with a source-tosample distance of $40 \mathrm{~cm}$ using an x-ray machine (GE 1000; General Electric, Milwaukee, WI, USA). Three exposures were done for each sample. The radiographs were transferred from the phosphor plate to the computer via a Digora scanner (Digora Optime, Soredex, Helsinki, Finland).

The radiodensity (in pixels) of the samples was determined with the resident software provided by the manufacturer. The Digora system has a windows-based software, Digora for Windows 2.5 Rev 0 (Soredex, Helsinki, Finland), which is capable to measure density curves of digital radiographies obtained by $\mathrm{x}$-ray impregnation on the image phosphor plate. The radiodensity of each radiographed structure or material was obtained by clicking with the software cursor right above the digital image. Each digital image had it radiodensity measured immediately after scanning, without any modification in contrast or brightness. This software shows data concerning the highest and the lowest radiodensity of the sample, and an average value, which was considered to be the sample's initial radiodensity. Since each sample was subjected to three exposures the sample's final radiodensity was considered to be the mean of those values.

\section{DTS Test}

Five cylindrical specimens of each experimental group $(n=5)$ were prepared for the DTS test according to ADA specification no. 27. A $4.0 \mathrm{~mm}$ long and $8.0 \mathrm{~mm}$ diameter aluminum mold was used. Three minutes after filling the molds with mixed cements, samples were kept in $100 \%$ humidity and $37^{\circ} \mathrm{C}$ for $1 \mathrm{~h}$, followed by gentle removal from the mold and immersion in distilled water for $23 \mathrm{~h}$ prior to testing. A compressive load was applied on the diametral surface of the samples to obtain the DTS at a crosshead speed of $0.5 \mathrm{~mm} /$ min in a universal testing machine (Instron 4411; Instron Testing Instruments, Canton, MA, USA).

\section{Scanning Electron Microscopy Analysis (SEM)}

For observations of materials characteristics after complete setting, SEM analysis was accomplished in samples from Ortho Glass LC and Vitro Cem experimental groups. Fractured samples were sputter-coated with gold (MED 010; Balzers Union, Balzers, Liechtenstein) and observed with a scanning electron microscope (DSM 940A; Zeiss, Oberkoshen, Germany).

\section{Statistical Analysis}

Statistical analysis was performed in accordance with the results of Shapiro-Wilk test of normal distribution, with parametric or non-parametric tests, for each variable. One-way ANOVA followed by Tukey's Honestly Significant Difference (HSD) test was employed for DTS and the Kruskal-Wallis and Dunn's method for radiodensity, using the SPSS 12.0 for Windows statistical software (SPSS Inc., Chicago, IL, USA). Two-way ANOVA $(5 \times 2)$ followed by Tukey's HSD test, with a general linear model procedure, was also used to analyze the interaction between materials and $P / L$ ratio. For paired comparisons, independent samples t-test was used for DTS and Mann-Whitney Test for Radiodensity. The aluminum step was compared to each group by ANOVA and Dunnett's 2-sided test. For all tests, groups were considered statistically different at $a=09.05$.

\section{RESULTS}

Tables 1 and 2 show the results of DTS test (in $\mathrm{MPa}$ ) and radiodensity measurements (in pixels), respectively, together with the statistical analysis. Radiodensity means and standard deviations are presented only to facilitate the understanding. Since data were not normally distributed, the sum of the ranks (non-parametric analysis) is also provided. There was a significant interaction $(P=0.001)$ for the factors under study (materials vs. P/L ratio). Thus, a separate analysis was accomplished for the interactions.

DTS analysis for both levels of $P / L$ ratios showed that both RMGICs presented similarly higher values than GICs $(P<0.05$; Table 1$)$. Radiodensity analysis for manufacturer's recommended $P / L$ groups showed that two GICs (Vitro Molar and Vitro Fil) were more radiopaque than the other three. For 
Table 1- Diametral tensile strength (DTS) means and standard deviations (in MPa; $n=5$ ), and results of statistical analysis of groups by ANOVA, Tukey's HSD and T-test $(\alpha=0.05)$

\begin{tabular}{lcc}
\hline Groups & DTS mean(SD) for man. P/L & DTS mean(SD) for 0.5 P/L \\
\hline & & \\
Vitro Fil LC & $20.94(3.34)^{\mathrm{Aa}}$ & $11.20(2.84)^{\mathrm{Ab}}$ \\
Ortho Glass LC & $15.0(2.12)^{\mathrm{Aa}}$ & $10.94(1.87)^{\mathrm{Ab}}$ \\
Vitro Molar & $7.73(3.24)^{\mathrm{Ba}}$ & $4.08(1.32)^{\mathrm{Ba}}$ \\
Vitro Fil & $7.01(3.21)^{\mathrm{Ba}}$ & $4.19(1.57)^{\mathrm{Ba}}$ \\
Vitro Cem & $2.83(0.71)^{\mathrm{Ba}}$ & $2.37(0.66)^{\mathrm{Ba}}$ \\
\hline
\end{tabular}

* Different uppercase letters indicate significant differences within the same P/L ratio groups (vertical comparison only $\mathrm{P}<0.05)$. † Different lowercase letters indicate significant differences within the same material varying $P / L$ ratio (horizontal comparison only $-\mathrm{P}<0.05)$ ) $\ddagger$ man. $\mathrm{P} / \mathrm{L}$ : manufacturer's recommended $\mathrm{P} / \mathrm{L}$ ratio. $\S 0.5 \mathrm{P} / \mathrm{L}: 50 \%$ reduced $\mathrm{P} / \mathrm{L}$ ratio

Table 2- Radiodensity means, standard deviations (SD) (in pixels; $n=15$ ) and sum of the ranks, and results of statistical analysis by Kruskal-Wallis test, Dunn's method, and Mann-Whitney Test $(\alpha=0.05)$

\begin{tabular}{|c|c|c|c|c|c|c|}
\hline \multirow[t]{2}{*}{ Groups } & \multicolumn{2}{|c|}{ Mean(SD) } & \multicolumn{2}{|c|}{$\begin{array}{c}\text { Sum of Ranks } \\
\text { (Vertical comparison) }\end{array}$} & \multicolumn{2}{|c|}{$\begin{array}{c}\text { Sum of Ranks } \\
\text { (Horizontal comparison) }\end{array}$} \\
\hline & $\begin{array}{l}\text { Man. P/L } \\
\text { ratio }\end{array}$ & $0.5 \mathrm{P} / \mathrm{L}$ & $\begin{array}{l}\text { Man. P/L } \\
\text { ratio }\end{array}$ & $0.5 \mathrm{P} / \mathrm{L}$ & $\begin{array}{l}\text { Man. P/L } \\
\text { ratio }\end{array}$ & $0.5 \mathrm{P} / \mathrm{L}$ \\
\hline Vitro Molar & $200.44(10.34)$ & $175.19(9.32)$ & $61.00 \mathrm{~A}$ & 53.67AB & $22.6 a$ & $8.4 b$ \\
\hline Vitro Fil & $200.14(6.34)$ & 191.63(10.1) & $59.87 A$ & $66.6 \mathrm{~A}$ & $20.0 a$ & $11.0 \mathrm{~b}$ \\
\hline Vitro Fil LC & $171.09(5.36)$ & $139.14(12.77)$ & $25.80 \mathrm{~B}$ & $18.8 \mathrm{C}$ & $23.0 a$ & $8.0 \mathrm{~b}$ \\
\hline Vitro Cem & $168.12(8.79)$ & $146.42(6.61)$ & 23.87B & $33.2 \mathrm{BC}$ & $22.47 a$ & $8.53 b$ \\
\hline Ortho Glass LC & $164.87(12.34)$ & $136.07(7.19)$ & 19.47B & $17.73 \mathrm{C}$ & $22.53 a$ & $8.47 b$ \\
\hline
\end{tabular}

* Different capital letters mean significant differences within the same $\mathrm{P} / \mathrm{L}$ ratio groups (vertical comparison only $-\mathrm{P}<0.05$ ). $\dagger$ Different lower case letters mean significant differences within the same material varying P/L ratio (horizontal comparison only $-\mathrm{P}<0.05)$.

‡ Man.P/L ratio: manufacturer's recommended $\mathrm{P} / \mathrm{L}$ ratio.

$\S 0.5 \mathrm{P} / \mathrm{L}: 50 \%$ reduction in $\mathrm{P} / \mathrm{L}$ ratio.

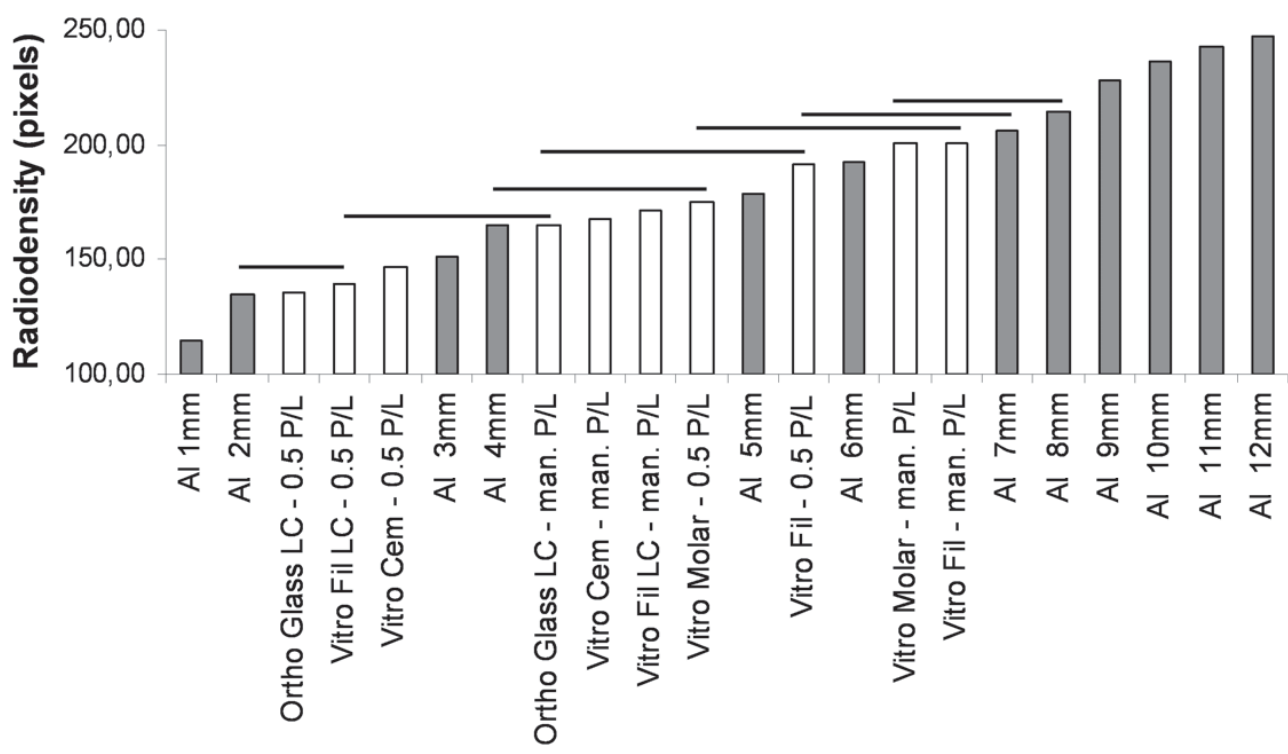

Figure 2- Comparison between experimental groups and aluminum stepwedge

* Means connected by the same horizontal line are similar by the ANOVA and Dunnett's 2-sided Test (P>0.05). A1-A12:

1.0-12.0 mm thick aluminum 


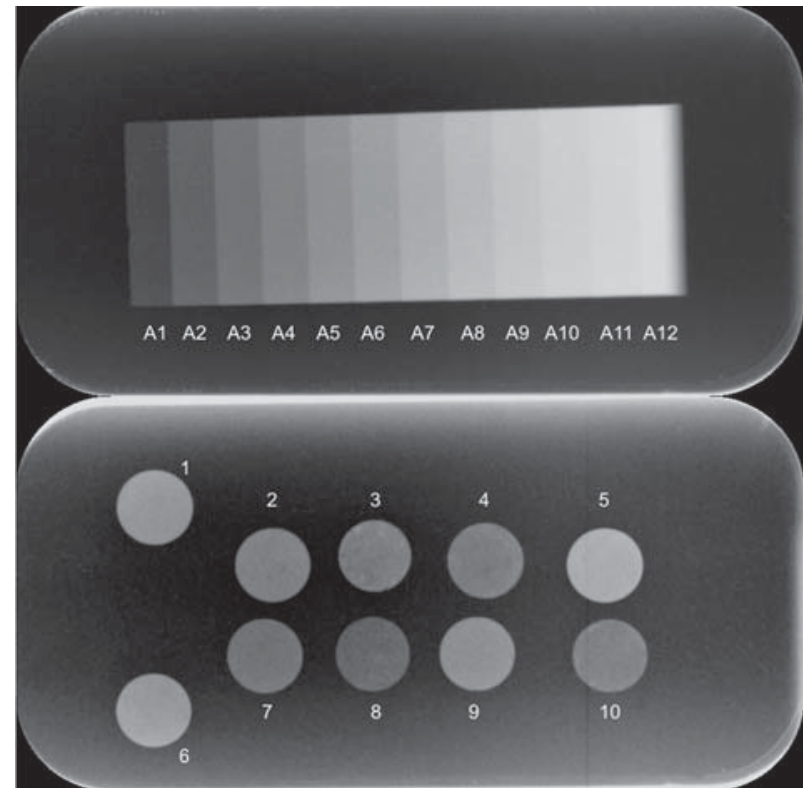

Figure 3- Digital radiograph of the studied materials and aluminum step wedge. 1: Vitro Molar - manufacturer's recommended $\mathrm{P} / \mathrm{L}$ ratio; 2 : Vitro Molar $-50 \%$ reduced P/L ratio; 3: Vitro Cem - manufacturer's recommended $\mathrm{P} / \mathrm{L}$ ratio; 4: Vitro Cem $-50 \%$ reduced $\mathrm{P} / \mathrm{L}$ ratio; 5: Vitro Fil - manufacturer's recommended P/L ratio; 6: Vitro Fil $50 \%$ reduced $P / L$ ratio; 7 : Ortho Glass $L C$ - manufacturer's recommended P/L ratio; 8: Ortho Glass LC - 0.5P/L; 9:Vitro Fil LC - manufacturer's recommended P/L ratio; 10: Vitro Fil LC - 50\% reduced P/L ratio; A1-A12: 1.0-12.0 mm thick aluminum

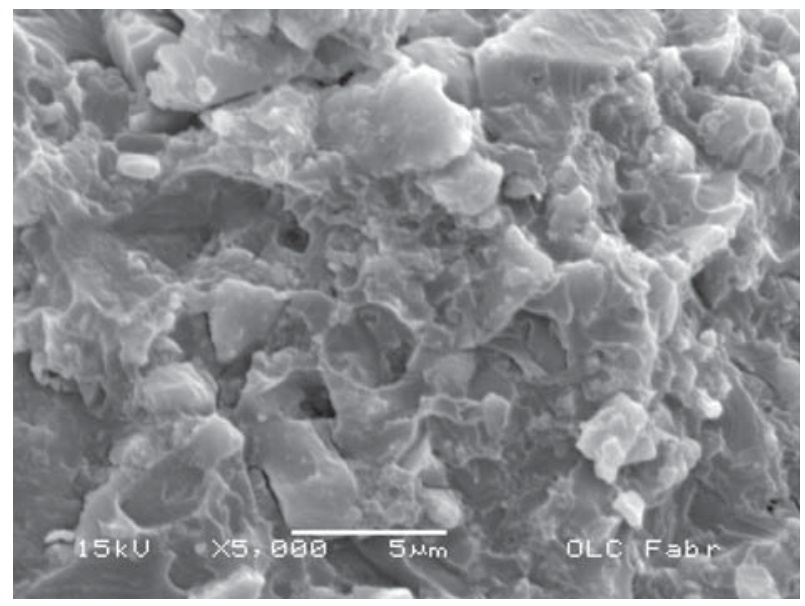

Figure 4- Scanning electron microscopy of Ortho Glass LC at manufacturer's recommended $P / L$ ratio showing a uniform interaction between resin matrix, salt matrix and unreacted powder particles, without clear signals of crack propagation. Note that the boundaries of powder particles cannot be clearly seen, which mean that the acid base reaction progressed in a free condition

the $50 \%$ reduced $\mathrm{P} / \mathrm{L}$ groups, Vitro Fil and Vitro Molar were again the most radiopaque materials, but the last was similar to Vitro Cem, and this one

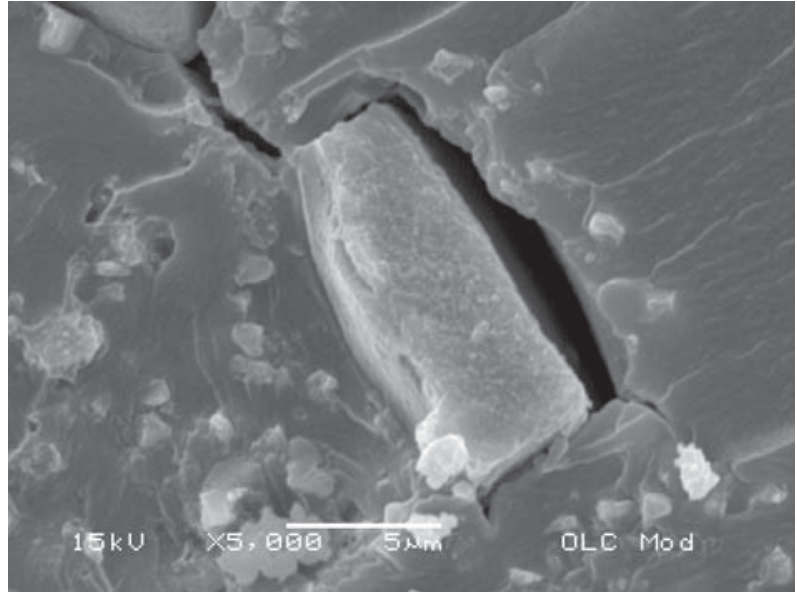

Figure 5- Scanning electron microscopy Ortho Glass LC at $50 \%$ reduced $P / L$ ratio showing a greater volume of matrix around powder particles; particle's boundaries can be clearly seen, which mean that the acid-base reaction was partially inhibited by the greater presence of resin. Note the presence of crack propagation around the powder particle, which is related to a lower interaction between matrix-powder

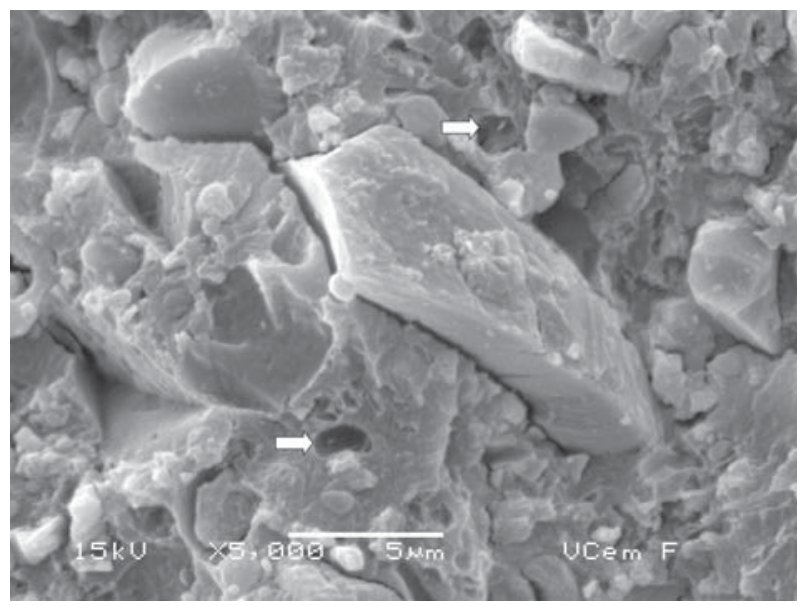

Figure 6- Scanning electron microscopy of Vitro Cem at manufacturer's recommended $P / L$ ratio showing the presence of big powder particles surrounded by salt matrix. Note the presence of bubbles inside the mixture (white arrows), and cracks walking around unreacted powder particles

was similar to the RMGICs (Table 2).

Within each material, pairwise DTS analysis by t-test showed that reducing the $P / L$ ratio resulted in a significant reduction in strength just for Ortho Glass LC and Vitro Fil LC, with $27.1 \%$ and $46.6 \%$ of reduction, respectively. Pairwise radiodensity analysis by the Mann-Whitney Test showed that reducing the $P / L$ ratio resulted in a significant reduction in radiodensity for all materials. Figure 2 presents the comparison between the aluminum stepwedge and experimental groups. Figure 3 shows a radiographic image of the groups and 


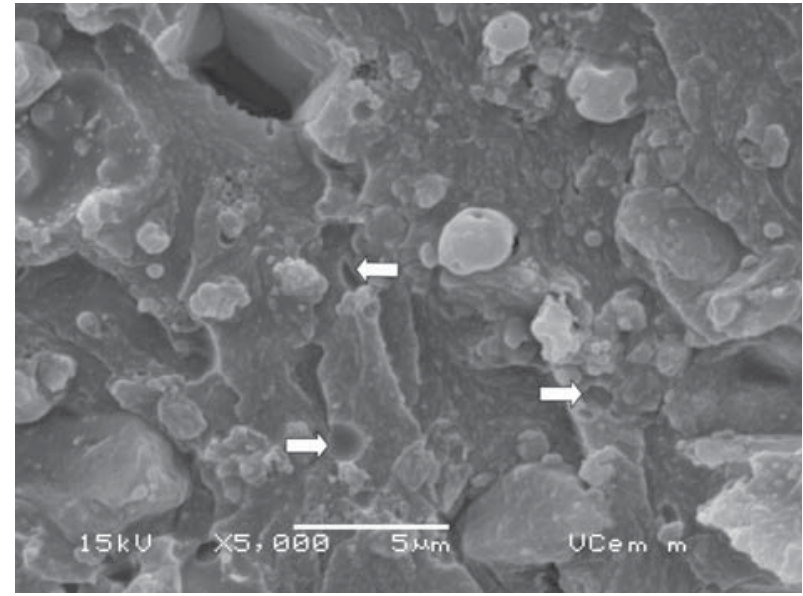

Figure 7- Scanning electron microscopy of Vitro Cem at $50 \%$ reduced $P / L$ ratio showing the presence of small unreacted powder particles embedded by a great amount of salt matrix. Note the presence of bubbles (white arrows) and a close interaction between particles and the matrix

the aluminum stepwedge. During mixing of the cements, it was noted that Vitro Molar and Vitro Fil were difficult to mix at the manufacturer's recommended $\mathrm{P} / \mathrm{L}$ and the mixed material resulted in a rough mass. At $50 \%$ reduced $P / L$ ratio, it was easier to mix these materials and a smooth mass was obtained.

Figures 4 and 5 are SEM images of Ortho Glass LC at the manufacturer's recommended $\mathrm{P} / \mathrm{L}$ and the $50 \%$ reduced $\mathrm{P} / \mathrm{L}$ ratio, respectively. Figures 6 and 7 of Vitro Cem at the manufacturer's recommended $P / L$ ratio and $50 \%$ reduced $P / L$ ratio, respectively. For the RMGICs, reduction in liquid at $50 \% \mathrm{P} / \mathrm{L}$ resulted in poor interaction between matrix and powder particles with clear signs of crack development. For the conventional GICs, reduction in liquid at $50 \% \mathrm{P} / \mathrm{L}$ ratio resulted in a greater presence of salt matrix and its close interaction with powder particles without the development of cracks, which could be seen at the manufacturer's recommended $\mathrm{P} / \mathrm{L}$.

\section{DISCUSSION}

Several factors can have an influence on conventional GIC and RMGIC properties, but the P/L ratio $^{9,13}$ is the one that relies on the responsibility of clinicians ${ }^{11}$. The hypothesis driven on this study was confirmed with the observed alterations in DTS and radiodensity of GICs and RMGICs due to changes in $\mathrm{P} / \mathrm{L}$ ratio. The assumption that radiodensity depends more on the composition of dental materials than the type of material ${ }^{5}$ was confirmed and the DTS results are in general agreement with other studies ${ }^{23,24}$, who reported that the RMGICs exhibited higher DTS than GICs. Composition, setting reactions, materials' maturation and microstructures seemed to be the principal reasons for these observations.

Materials tested with the same thickness mostly vary in radiodensity by the influence of composition ${ }^{5}$. $\mathrm{X}$-ray beam interactions with the matter are always directly proportional to either the atomic number of the absorber or to its electric density ${ }^{8}$; then depending on the atomic composition and density of each atom in the matter a radiographic image will be differently influenced. The addition of chemical elements with high atomic numbers such as zinc, strontium, zirconium, barium and lanthanum result in more radiopaque materials ${ }^{5,9,10}$. RMGICs are not always radiopaque ${ }^{10}$ and GICs are usually radioluscent ${ }^{9,10}$.

Vitro Molar and Vitro Fil, which present barium/ $\mathrm{FeO}$ and strontium/FeO, respectively, in their composition, were the most radiopaque materials, when mixed in the manufacturer's recommended $\mathrm{P} / \mathrm{L}$ ratio. However, even with the presence of strontium/FeO in the other materials, their radiodensity were similarly lower than the previous mentioned ones, which mean these components are present in relatively lower quantities. With the reduced $\mathrm{P} / \mathrm{L}$ ratio, Vitro Fil and Vitro Molar still presented the highest radiodensity levels, but Vitro Cem was similar to Vitro Molar and the RMGICs were similar to Vitro Cem. Vitro Molar is a restorative GIC and is more viscous than Vitro Cem. The higher viscosity and the apparent presence of more quantities of radiopaque fillers would render higher radiodensity, but with the reduction in $\mathrm{P} / \mathrm{L}$ ratio, these differences disappeared. Since organic components do not seem to offer radiopaque characteristics to dental materials ${ }^{5}$, the observed lower radiodensity for RMGICs at $50 \%$ reduced $P / L$ ratio is a direct cause of the increase in liquid per volume. Within each material, the reduction in $\mathrm{P} / \mathrm{L}$ ratio significantly reduced the radiodensity of all materials in this study (Table 2), and this also may be a direct result of the increase in liquid per volume. Since all materials employed on the present study, irrespective of the $P / L$ ratio being similar or more radiopaque than $A 2$ or $A 3$ aluminum steps (Figure 2), they could eventually be detected against an enamel background (good clinical property $)^{5,9,10}$.

Generally, chain displacement can occur at sufficiently high stress in deformable polymers, than in brittle polymeric and ceramic materials, which undergo crack propagation at high stress ${ }^{3,19}$. Mitsuhashi, et al. ${ }^{15}$ (2003) showed that when the P/L ratio is decreased and the matrix volume increased as a consequence, the characteristics of the resin matrix are significantly emphasized for the RMGICs. It is expected that greater presence of resin in RMGICs, by reduction of $\mathrm{P} / \mathrm{L}$ ratio, would render a material with more viscoelastic behavior, greater strain capacity and possibly greater resistance to 
stress development by load application. However, even if a more viscoelastic behavior is expected, the tendency for generating materials which withstand less load application is real because in the cement mixtures, the volume fraction of the matrix, which has weak mechanical strength, increases at lower $\mathrm{P} / \mathrm{L}$ ratios. Irrespective of the $\mathrm{P} / \mathrm{L}$ ratio, this study showed that RMGICs' strength was always higher than that of conventional GICs (Table 1), possibly due to the greater expected viscoelastic behavior of RMGICs and the higher cohesive strength of resin matrix versus salt matrix ${ }^{23}$. On the other hand, DTS was reduced only for RMGICs when $50 \%$ reduced $\mathrm{P} / \mathrm{L}$ ratio was employed (Table 1 ).

When comparing RMGICs and GICs, Yamazaki, et al. ${ }^{24}$ (2006) showed they possess similar viscoelastic behavior, irrespective of the polymeric character of RMGICs. Then, it is possible that resin and salt matrixes act similarly, in these materials, with a higher probability of enabling plastic deformation for the former ${ }^{23}$. However, Mitsuhashi, et al. ${ }^{15}$ (2003) found that the fracture toughness of the RMGICs is not greatly influenced by the P/L ratio, as it is for GICs. Only at high reductions in $P / L$ ratio, the fracture toughness started to decrease for RMGICs ${ }^{15}$. With lower fracture toughness materials became more brittle, reducing plastic behavior and also the resistance against crack propagation ${ }^{15}$. Thus, differently from GICs, a significant alteration in RMGICs properties is only expected with high reduction of powder amount, because the acidbase reaction of the powder particle and liquid is critical for many physical properties of hardened materials ${ }^{15}$. The SEM analysis showed an integrated microstructure for RMGICs with manufacturer's recommended $\mathrm{P} / \mathrm{L}$ ratio (Fig 3), but the same was not true for $50 \%$ reduced $\mathrm{P} / \mathrm{L}$ ratio, which showed a greater presence of matrix per volume, unreacted particles and crack development, recognized as a signal of the jeopardized interaction between matrix and powder particles (Figure 5). The high reduction in $\mathrm{P} / \mathrm{L}$ ratio, as performed in the present study, resulted in significantly lower DTS values just for RMGICs, and not for conventional GICs (Table 1). In spite of that, for all materials, a decrease in DTS occurred with the reduction in $\mathrm{P} / \mathrm{L}$ ratio. There are two possibilities to explain this result. One is that limitations of the experimental design did not allow differences between manufacturer's recommended $P / L$ ratio and $50 \%$ reduced $P / L$ ratio of the materials to be observed. Larger sample sizes may possibly be necessary to demonstrate statistically significant differences. The other possibility is closely related to the setting reactions of each type of material.

For light-cured GICs, the maturation of cure by chemical setting has an important influence on the physical properties of the hardened materials ${ }^{15}$ because an increase in the overall properties is observed with material's maturation ${ }^{25}$. More integrated microstructures with better glass particlepolymer matrix bonding, results in higher values of DTS ${ }^{23}$, which could be seen in manufacturer's recommended $\mathrm{P} / \mathrm{L}$ ratio (Figure 2 ). Adusei, et al. ${ }^{1}$ (2004) showed that the use of silanated glass in polyacid-modified resin composites results in a decrease in flexural strength because not all particles seem to participate of the setting reaction. This leads to a less cohesive matrix, and the same situation is expected on RMGICs, which leads to the conclusion that there is an important role of the salt part of the matrix in the overall strength of these materials ${ }^{1}$.

It is speculated, from the DTS results of the present study that a high reduction in $\mathrm{P} / \mathrm{L}$ ratio leads to a more fluid mass, where the completion of the chemical reaction is reduced through the polymerization of the resinous part, as previously stated by Yelamanchili and Darvel ${ }^{26}$ (2008). Even if the chemical reaction is generally able to keep going after light polymerization ${ }^{14}$, it seems a greater volume of resin by reduction in $\mathrm{P} / \mathrm{L}$ ratio, entraps polyacid molecules, and the so important chemical reaction reduces in effectiveness. According to Peutzfeldt, et al. ${ }^{17}$ (1997) HEMA molecule crosslinking keeps the carboxylate groups of different polyacid chains too far apart to be crosslinked via $\mathrm{Ca}^{+2}$ as will normally happen without resin. Since chemical and light irradiated network formation compete ${ }^{26}$, but with $50 \%$ reduced $\mathrm{P} / \mathrm{L}$ ratio the chemical reaction is slowed down, strength of final product will be negatively influenced. In addition, the higher proportion of the resinous part does not assure better mechanical properties because light irradiation results in a temperature rise, potentially permitting a higher value of the "auto-limiting" glass-transition temperature, with a consequent negative effect of degree of conversion ${ }^{26}$. Figure 5 shows an apparent ineffective interaction between particles and matrix as a result of the "HEMA blocking effect".

The assumption that both the salt matrix and the resinous matrix have a determinant relationship in the overall strength of RMGICs ${ }^{1,26}$ was confirmed in this study, but needs more specific studies to be proved. The reduction in $\mathrm{P} / \mathrm{L}$ ratio for GICs did not result in significantly lower DTS, which mean that the polyacid is able to react with normally unreacted glass particles and the greater presence of salt matrix does not significantly reduces strength. SEM analysis showed a lower presence of salt matrix in manufacturer's recommended $P / L$ ratio (Figure 6 ) and clear signs of cracks around unreacted powder particles, which mean a high tendency for brittle characteristics in these ionomers. At 50\% reduced $\mathrm{P} / \mathrm{L}$ ratio (Figure 7 ) a greater presence of salt matrix can be seen, with smaller particles and no signals 
of cracks. These observations led to the assumption that even if a better interaction between matrix and powder particles is seen when more liquid is added to the mixture, GICs' DTS can be considered more stable when alterations in $\mathrm{P} / \mathrm{L}$ ratio are performed, since different morphological structures are formed and can resist differently to load application. However, the reduction in absolute DTS means for Vitro Molar and Vitro Fil should be taken into consideration, meaning that more salt matrix can possibly result in poor mechanical properties with time. Further studies are necessary to prove this hypothesis. The use of the manufacturers' recommended $P / L$ ratio is always advisable since properties will be preserved.

\section{CONCLUSIONS}

From the results of this study it is possible to conclude that: 1 . Alterations in the $\mathrm{P} / \mathrm{L}$ ratio should be avoided since a decrease in radiodensity and DTS was seen; 2. RMGICs had a significant decrease in DTS, but all materials were affected in their radiodensity due to alterations in $\mathrm{P} / \mathrm{L}$ ratio; 3. The DTS of RMGICs seems to be highly influenced by structural organization (organic molecules and inorganic particles), while radiodensity is affected by chemical composition.

\section{ACKNOWLEDGEMENTS}

Authors are grateful to DFL for full donation of the materials used in this study, and to CAPES-Brazil (Coordenadoria de Aperfeiçoamento de Pessoal de Nível Superior) for Rodrigo B. Fonseca PhD program support.

\section{REFERENCES}

1- Adusei GO, Deb S, Nicholson JW. The role of the ionomer glass component in polyacid-modified composite resin dental restorative materials. J Mater Sci Mater Med. 2004;15(7):751-4.

2- Celiberti P, Lussi A. Penetration ability and microleakage of a fissure sealant applied on artificial and natural enamel fissure caries. J Dent. 2007;35(1):59-67.

3- Craig R. Restorative dental materials. St. Louis: Elsevier; 2001. 4- el-Mowafy OM, Benmergui C. Radiopacity of resin-based inlay luting cements. Oper Dent. 1994;19(1):11-5.

5- Fonseca RB, Branco CA, Soares PV, Correr-Sobrinho L, HaiterNeto F, Fernandes-Neto AJ, et al. Radiodensity of base, liner and luting dental materials. Clin Oral Investig. 2006;10(2):114-8.
6- Forsten L. Fluoride release and uptake by glass-ionomers and related materials and its clinical effect. Biomaterials. 1998;19(6):503-8.

7- Gladys S, Van Meerbeek B, Braem M, Lambrechts P, Vanherle $\mathrm{G}$. Comparative physico-mechanical characterization of new hybrid restorative materials with conventional glass-ionomer and resin composite restorative materials. J Dent Res. 1997;76(4):883-94. 8- Goaz PW, White SC. Oral radiology. St. Louis: C.V. Mosby; 1987. 9- Hara AT, Serra MC, Haiter-Neto F, Rodrigues AL Jr. Radiopacity of esthetic restorative materials compared with human tooth structure. Am J Dent. 2001;14(6):383-6.

10- Hara AT, Serra MC, Rodrigues AL Jr. Radiopacity of glassionomer/composite resin hybrid materials. Braz Dent J. $2001 ; 12(2): 85-9$.

11- Hibino Y, Kuramochi K, Hoshino T, Moriyama A, Watanabe $\mathrm{Y}$, Nakajima $\mathrm{H}$. Relationship between the strength of glass ionomers and their adhesive strength to metals. Dent Mater. 2002;18(7):552-7.

12- Hotz P, McLean JW, Sced I, Wilson AD. The bonding of glass ionomer cements to metal and tooth substrates. $\mathrm{Br}$ Dent J. $1977 ; 142(2): 41-7$.

13- Irie M, Tjandrawinata R, Suzuki K, Watts DC. Root-surface gap-formation with RMGIC restorations minimized by reduced $\mathrm{P} / \mathrm{L}$ ratio of the first increment and delayed polishing. Dent Mater. 2006;22(5):486-97.

14- McCabe JF. Resin-modified glass-ionomers. Biomaterials. 1998;19(6):521-7.

15- Mitsuhashi A, Hanaoka K, Teranaka T. Fracture toughness of resin-modified glass ionomer restorative materials: effect of powder/liquid ratio and powder particle size reduction on fracture toughness. Dent Mater. 2003;19(8):747-57.

16- Nicholson JW. Chemistry of glass-ionomer cements: a review. Biomaterials. 1998;19(6):485-94.

17- Peutzfeldt A, García-Godoy F, Asmussen E. Surface hardness and wear of glass ionomers and compomers. Am J Dent. $1997 ; 10(1): 15-7$.

18- Piwowarczyk A, Ottl P, Lauer HC, Büchler A. Laboratory strength of glass ionomer cement, compomers, and resin composites. J Prosthodont. 2002;11(2):86-91.

19- Rosen SL. Fundamental principles of polymeric materials. New York: John Wiley \& Sons; 1993.

20- Sidhu SK, Shah PM, Chong BS, Pitt Ford TR. Radiopacity of resin-modified glass-ionomer restorative cements. Quintessence Int. $1996 ; 27(9): 639-43$.

21- Turgut MD, Attar N, Onen A. Radiopacity of direct esthetic restorative materials. Oper Dent. 2003;28(5):508-14.

22- Uno S, Finger WJ, Fritz U. Long-term mechanical characteristics of resin-modified glass ionomer restorative materials. Dent Mater. $1996 ; 12(1): 64-9$.

23- Xie D, Brantley WA, Culbertson BM, Wang G. Mechanical properties and microstructures of glass-ionomer cements. Dent Mater. $2000 ; 16(2): 129-38$.

24- Yamazaki T, Schricker SR, Brantley WA, Culbertson BM, Johnston W. Viscoelastic behavior and fracture toughness of six glass-ionomer cements. J Prosthet Dent. 2006;96(4):266-72.

25- Yap AU, Pek YS, Cheang P. Physico-mechanical properties of a fast-set highly viscous GIC restorative. J Oral Rehabil. 2003;30(1):1-8.

26- Yelamanchili A, Darvell BW. Network competition in a resinmodified glass-ionomer cement. Dent Mater. 2008;24(8):1065-9. 